\title{
China's "left behind" children often suffer health consequences
}

Published at www.cmaj.ca on Sept. 30

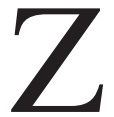

hang Sheng Yi was just a few months old when he was sent from his home, outside of Venice, Italy to Qingtian, a mountainous county in China's southeastern province of Zhejiang.

His father was a cook in a sushi restaurant and his mother a seamstress in a clothing factory. Struggling immigrants, overwhelmed and underpaid, they shipped their only son to China to be cared for by his paternal grandmother, Yu Mei Juan.

"There was no other option," says Yu. "My son and his wife were working very hard in Italy. Here, you see a lot of grandmothers raising their grandchildren. Some even take care of three or four children at a time."

Not just in Qingtian. Across China, millions of children have been left in the care of relatives in the countryside as their parents migrate to cities, or even abroad, to find work.

The rural exodus has been extraordinary. An estimated 130 million people have abandoned the countryside. In Qingtian alone, more than 200000 have gone overseas - mostly to Europe since 1979.

As a result, the Chinese government estimates that 23 million children under 14 years of age have been "left behind" in the countryside, usually in the care of grandparents.

Some groups, like the All-China Women's Federation, claim that number is even higher — closer to 60 million.

Leaving children in kinship care is a cultural norm in China, where extended families play an active role in child rearing.

But there are indications that there are consequences in terms of physical, psychological and even social health.

A survey of the nutritional intake of over 700 "left-behind" children in several rural provinces throughout China

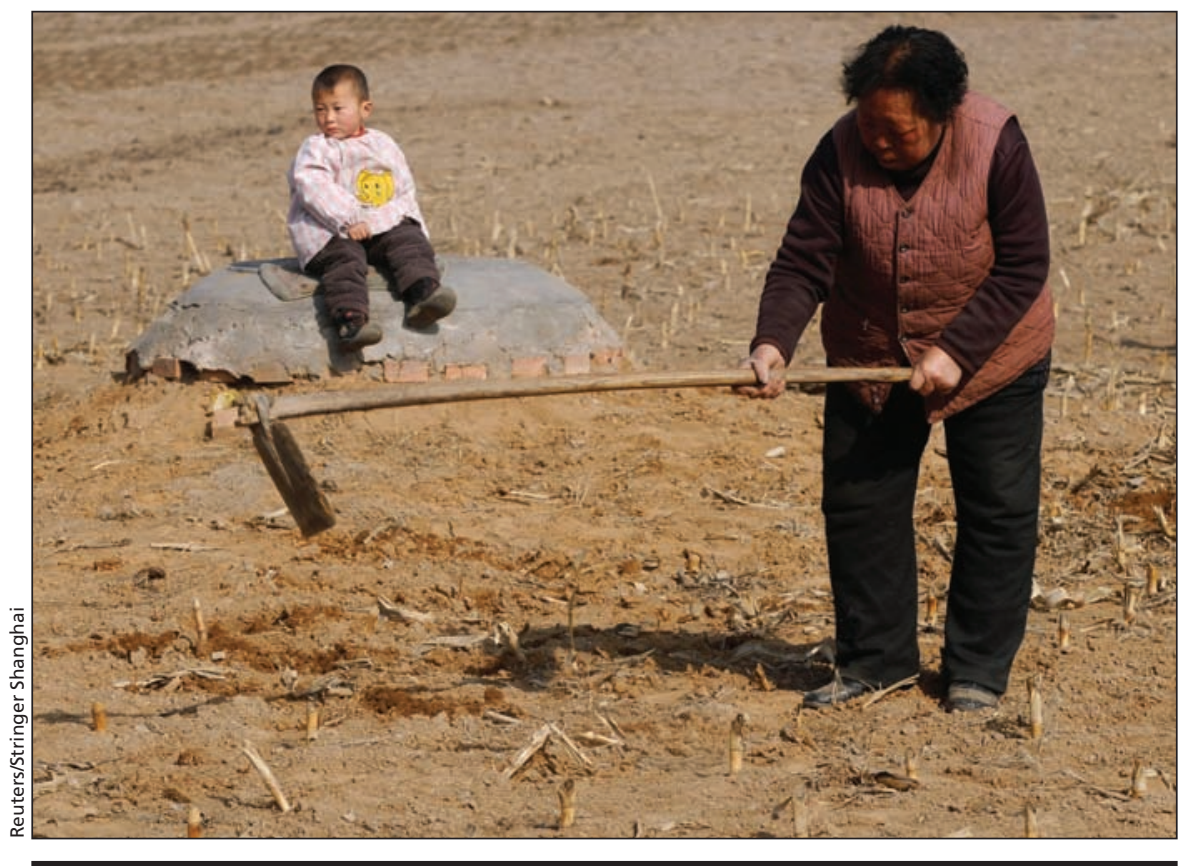

A Chinese gradmother works in a cornfield as her grandson sits nearby on the outskirts of Changzhi, Shanxi province.

found that their daily intake was notably lower than those raised by parents (Public Health Rep 2008;123[3]: 382-89).

They were also prone to higher rates of growth retardation and low body weight, suffered from stress as a result of prolonged separation from their parents, and frequently were left feeling indifferent and inferior. The authors indicated that the children were typically introverted, unsociable and prone to learning disabilities.

Another study, of 500 "left behind" children in central Henan Province, found that more than $50 \%$ were disatisfied with their living conditions and performed poorly in school (China Statistics 2005;1:59-60).

Leaving children in kinship care is "common throughout the developing world," says Dr. David Hipgrave, UNICEF's chief of health and nutrition in China. "If you've worked in Africa or India, you will know that if
Mom or Dad has an opportunity to go study or earn money ... basic material needs and opportunities like that are often given priority over something much less tangible like a relationship with a child."

To redress some of the problems, UNICEF has helped develop and fund a number of programs across China to promote the uptake of social services in this group, such as childhood vaccinations.

"Sometimes it's as simple as the grandma is too old or infirm or the aunt is unable, physically, to bring the child in for vaccinations," Hipgrave says. "Kids who are left with elder relatives, who may be less well-educated or illiterate, could also be at a higher risk of the same kind of nutritional issues those elders experienced when they were growing up."

Children "are not fed the right food or fed food that's easy to prepare packaged food that might be of low 
nutritional value, fast food, fatty foods, of foods that are full of carbohydrates," he adds.

Experts also agree that reform of China's household registration system, known as the hukou system, might help reduce the number of left-behind children.

The hukou is like an internal passport, which identifies the city, town or village to which a person belongs. This designation limits a person's ability to find legitimate work or access social services in another part of the country.
Migrant rural workers may live in a city for years without an "urban hukou." Until they get one, they aren't entitled to subsidized public housing, public medical insurance, government welfare cheques or public education beyond elementary school. So most opt to leave behind their children.

Yet, in the eyes of some, such as $\mathrm{Yu}$ Mei Juan, there are no adverse consequences to these children being left behind. Her grandson returned to Italy in late 2009 after more than a year in her care. She's now hoping for the birth of a second grandchild, who'd also be expected to spend his early years in Qingtian.

"It's better that my son sacrifices this time with his child to forge a stable life and future," Yu says. "They've enrolled my grandson in school for the fall and he's already picking up some Italian. He's doing just fine." - Suzanne Ma, Qingtian County, Zhejiang Province, China.

DOI:10.1503/cmaj.109-3674 